\title{
Revisión de artículos sobre floculación de microalgas
}

\section{A brief review about microalgae flocculation}

\author{
págs. 114-132 \\ Grupo de investigación: BiotecFUA \\ Línea de investigación: Aprovechamiento de residuos agroindustriales \\ Juan Sandoval Herrera• Diego Rubio Fernández••
}

\section{RESUMEN}

El artículo presenta una revisión cronológica del estado del arte en el tema de floculación de microalgas, desde los primeros trabajos para tratamiento de agua residual, hasta las investigaciones más recientes sobre tecnologías modernas, sustancias nuevas y procedimientos integrales. El análisis de la información se estructuró en dos partes: 1) revisión de publicaciones por país, donde se realizó la investigación, revista y evolución por año de las publicaciones, y 2) análisis más detallado de la clasificación de los artículos por especie de microalga; además, se consideró el floculante usado, así como las condiciones del proceso y los resultados destacados.

Palabras clave: floculación, microalgas, bioprocesos.

\begin{abstract}
In this paper, time evolution of publications about flocculation is presented, since the beginnings related to waste water treatment until new advances in technologies, new substances, and process integration. Information is analyzed in two parts: country where the investigation took place, source and number of publications by year. And, in the second part, information is classified according to microalgae specie, flocculant type, process conditions and outstanding results.
\end{abstract}

Key words: flocculation, microalgae, bioprocess.

- Ingeniero químico. Docente. juan.sandoval@profesores.uamerica.edu.co

•• Biólogo. Investigador. diego.rubio@profesores.uamerica.edu.co 
LÍNEA DE INVESTIGACIÓN: APROVECHAMIENTO DE RESIDUOS AGROINDUSTRIALES

\section{INTRODUCCIÓN}

Las microalgas son actualmente una fuente muy importante para la obtención de biodiesel, además de una gran variedad de productos de valor agregado de uso a nivel farmacéutico. También se usan en bioremediación para tratar aguas residuales o para atenuar concentraciones de gases tóxicos, dióxido de carbono, principalmente. En los casos en los que se quiere extraer productos de la microalga (y no solamente utilizarla como medio para remediación de contaminación) siempre será necesario una fase de cosechado en el proceso, porque la microalga se cultiva en medio acuoso, altamente diluido y los productos de esta se deben separar de la biomasa sin agua. Es ahí donde se presenta el cuello de botella del proceso, porque los costos son altos para realizarlo, debido al tamaño pequeño, alta dilución y relativamente baja densidad de las células. Las técnicas más diversas, asociadas a campos como el tratamiento de aguas residuales o la minería, se han empleado y desarrollado desde hace varios años; pero aún no hay conclusiones sobre cuál técnica sea la mejor según factores económicos, tecnológicos e, incluso, ecológicos.

La floculación es la primera etapa del proceso de cosechado de microalgas para obtención de la biomasa. Este proceso consiste en la unión o agrupación de sustancias que están dispersas en un medio líquido. Generalmente, es la segunda etapa en un proceso completo de coagulación-floculación y sedimentación, que busca separar las sustancias sólidas del medio líquido que las contiene. Entre más efectiva sea la floculación, la siguiente etapa, que puede ser centrifugación, flotación, separación magnética, filtración o alguna otra técnica más novedosa, requerirá menores gatos.

\section{METODOLOGÍA}

La búsqueda de la información se realizó por medio de la herramienta académica de Google, en la base de datos de Scopus y en el portal ResearchGate. Posteriormente, la información se organizó por orden cronológico. También se clasificó por revista y por año. En cuanto al análisis de la información, se tuvieron en cuenta los agentes floculantes y las condiciones del proceso, así como las especies de microalgas a las que se aplicaron, y se destacó los resultados obtenidos por los investigadores. El objetivo principal de esta revisión es ofrecer al lector una mirada a la evolución histórica y presentar las tendencias actuales y futuras de los estudios en el tema de la floculación de microalgas.

\section{RESULTADOS Y DISCUSIÓN}

\section{Evolución de la producción alrededor del tema de floculación de microalgas}

El primer trabajo del cual se pudo obtener información para esta revisión fue el de Tenney, Echelberger, Schuessler y Pavoni (1969); esta investigación buscaba remediar el "problema" de las microalgas que se acumulan en los sistemas de agua potable o de tratamiento de aguas residuales. Después, Tilton, Murphy y Dixon (1972) usaron polielectrolitos sintéticos, como poliacrilamida catiónica y sulfonato de poliestireno, entre otros, para flocular Chlorella ellipsoidia. Pelton y Allen (1983) fueron los primeros en combinar poliacrilamida más sales minerales como floculante, pero aplicada a la industria del papel. Otro trabajo que partió del tratamiento de aguas residuales fue el de Lavoie y de la Noüe (1983), quienes estudiaron el uso de quitosano para concentrar cultivos frescos de microalga, como parte de un sistema de tratamiento terciario de aguas residuales para obtener biomasa 
para alimento de peces. Sus resultados muestran más de $95 \%$ de eficiencia de floculación, con una dosificación inferior a $40 \mathrm{mg} / \mathrm{L}$ de quitosano a temperaturas entre 5 y $25{ }^{\circ} \mathrm{C}$.

Shelef, Sukenik y Green (1984) publicaron la primera revisión acerca del tema: Microalgae Harvesting and Processing: A Literature Review. A la época, los únicos métodos o técnicas usadas eran la centrifugación, la filtración, la sedimentación, la flotación y la floculación. Al año siguiente, Morales, de la Noüe y Picard (1985) presentaron los resultados de la floculación de cinco especies de microalgas marinas, usando quitosano como floculante. $Y$ entre sus resultados se destaca un $100 \%$ de eficiencia de floculación con $40 \mathrm{mg}$ de floculante por litro de medio de cultivo, a pH de 7,8 a 8. Al reducir el pH por debajo de 7 , se consiguió el mismo porcentaje de eficiencia para Chlorella sp. con la mitad de dosis de floculante: $20 \mathrm{mg} / \mathrm{L}$. Otros autores que aportaron al tema durante los ochenta fueron Sukenik, Bilanovic, y Shelef (1988) y Bilanovic, Shelef y Sukenik (1988).

Jiang, Graham y Harward (1993) presentaron los resultados de su comparación de sulfato férrico, sulfato de aluminio, policloruro de aluminio y sulfato poliférrico (o PFS, por sus siglas en inglés) ${ }^{1}$. Hallaron mejores resultados con este último que con los floculantes tradicionales. Lee et ál. (1998) publicaron los resultados de su evaluación de tres métodos de floculación: ajuste de $\mathrm{pH}$, sulfato de aluminio y Pestan®, un biopolímero floculante.

Knuckey, Brown, Robert y Frampton (2006) compararon la floculación con cloruro férrico, con la floculación inducida por pH por medio de adición de $\mathrm{NaOH}$, para concentrar biomasa de microalgas marinas (cinco especies) con miras a la alimentación animal. Harith et ál. (2009) emplearon varios floculantes, entre ellos hidróxido de sodio con Magnafloc ${ }^{\circledR}$ (un floculante comercial) y quitosano, ensayando sobre Chaetoceros calcitrans y probaron a varias dosis y condiciones. Renault, Sancey, Badot y Crini (2009) publicaron una revisión muy completa sobre el tema del quitosano, como uno de los biofloculantes más importantes, comparado con sales de aluminio.

Ahmad, Yasin, Derek y Lim (2010) presentaron en una conferencia los resultados de su trabajo con Moringa oleífera y quitosano para coagular y/o flocular Chlorella vulgaris, previo a una separación por micro filtración, para averiguar si este pretratamiento evitaba la obstrucción de los poros de la membrana; no obstante, los resultados no fueron positivos y solamente se pudo sacar en limpio que el quitosano da mejores resultados en aumento de tamaño de los flóculos que la moringa, en las condiciones de ese trabajo. Vandamme, Foubert, Meesschaert y Muylaert (2010) publicaron los resultados de su estudio con dos almidones catiónicos comerciales (Greenfloc 120, de grado de sustitución 0,15, y Cargill, de grado de sustitución 0,122), con dos especies de microalgas de agua dulce (Parachlorella kessleri y Scenedesmus obliquus) y dos de agua salada (Phaeodactylum tricornutum y Nannochloropsis salina). Su conclusión fue que el almidón de mayor grado de sustitución (Greenfloc 120) da buenos resultados con microalgas de agua dulce, pero no con las de agua salada. Papazi, Makridis y Divanac (2010) evaluaron doce coagulantes de naturaleza mineral: cloruros y sulfatos de hierro, aluminio y zinc, para sedimentar la microalga marina Clorella minutissima, siendo los mejores las sales de aluminio, seguidas de las de hierro y de zinc. Cheng, Zheng, Labavitch y Vandergheynst (2011) evaluaron el impacto de la composición de la pared celular de la microalga Chlorella variabilis sobre la floculación, usando quitosano como floculante a diferentes $\mathrm{pH}(8,5$ fue el mejor $\mathrm{pH}$ ), y concluyeron que el contenido de carbohidratos totales afectaba positivamente la eficiencia de floculación.

1 Para la fecha de la publicación de la investigación de Jiang, Graham y Harward (1993), el sulfato poliférrico era un compuesto nuevo. 
LÍNEA DE INVESTIGACIÓN: APROVECHAMIENTO DE RESIDUOS AGROINDUSTRIALES

Schlesinger et ál. (2012) demostraron con su trabajo experimental que el pH no debe ser tan alto como se pensaba para facilitar la floculación, y que la relación entre dosificación de floculante y eficiencia de floculación no es lineal, sino de tipo logarítmica. Granados, Acien, Gómez, FernándezSevilla y Molina (2012) evaluaron una variedad de coagulantes-floculantes en cinco especies de microalgas de agua fresca (dulce): Muriellopsis sp., Chlorella vulgaris, Chlorella fusca, Scenedesmus subspicatus y Scenedesmus sp. Los autores concluyeron que la dosis adecuada dependía del tipo de microalga, además de otros factores, y que las eficiencias de floculación de floculantes aniónicos y no iónicos son bajas. Teixeira, Kirsten y Teixeira (2012) evaluaron la harina de semilla de moringa para flocular Chlorella vulgaris; los investigadores encontrando que, para este floculante, la eficiencia es directamente proporcional al $\mathrm{pH}$ y que la dosis óptima de moringa era $1 \mathrm{~g} / \mathrm{L}$. Zheng et ál. (2012) presentaron los resultados de su evaluación del ácido alfa glutámico (ácido 2-aminopentanodioico) como agente floculante y encontraron que su eficiencia era similar a la de las sales minerales, con una dosificación similar, pero su aplicación se da sobre todo para microalgas de agua marina.

Gerde, Yao, Lio, Wen y Wang (2013) ensayaron tres floculantes: sulfato de aluminio, almidón modificado de grado de sustitución 0,2 y almidón modificado de grado de sustitución 0,5, para concentrar biomasa de tres especies de microalgas: Scenedesmus spp., Chlamydomonas reinhardtii y Schizochytrium limacinum, y encontraron mejores resultados con los almidones modificados, especialmente con el de mayor grado de sustitución.

Vandamme (2013) trabajó en su tesis doctoral las técnicas de cosechado de microalga Chlorella vulgaris, en la que definió los aspectos más importantes de centrifugación, flotación y, sobre todo, floculación; asimismo, Vandamme, Foubert y Muylaert (2013) elaboraron una revisión sobre la floculación como base de los procesos de cosechado y Beuckels, Depraetere, Vandamme, Smolders y Muylaert (2013) publicaron un artículo sobre la influencia de la materia orgánica producida por las células microalgales cuando se someten a estrés en el proceso de floculación.

Chen, Wang, Wang y Wei (2013) estudiaron las mejores condiciones de pH, tipo y dosificación de floculante y tiempo de sedimentación para flocular Scenedesmus sp., comparando alumbre, quitosano, $\mathrm{FeCl}_{3}$ y $\mathrm{Al}_{2}\left(\mathrm{SO}_{4}\right)_{3}$. Los autores encontraron que para una concentración de biomasa inicial de 0,66 g/L la dosis óptima de alumbre y quitosano es 0,2 y $0,1 \mathrm{~g} / \mathrm{L}$, respectivamente. Li y Pan (2013) mostraron los resultados de su estudio de modificación de arenas marinas con harina de semilla de moringa, y en algunos casos con quitosano, para flocular o sedimentar algas marinas indeseadas, como la Amphidinium carterae.

Rashid, Rehman y Han (2013a) evaluaron la dosis efectiva de quitosano para flocular Chlorella vulgaris y encontraron que $120 \mathrm{mg} / \mathrm{L}$, con un $\mathrm{pH}$ de 6 , tenia una eficiencia del $99 \%$, aproximadamente. En un segundo trabajo, Rashid, Rehman y Han (2013b) usaron soluciones ácidas de quitosano para encontrar cuál era el mejor disolvente y en qué etapa del desarrollo de la microalga daba mayores eficiencias. Otro trabajo relacionado con quitosano fue el de Zhu, Dunford y Goad (2013), que analizó el efecto de las condiciones de procesamiento sobre la floculación de Picochlorum oklahomensis. Anthony et ál. (2013) compararon diferentes técnicas para flocular Scenedesmus obliquus; por ejemplo: la floculación química con polímeros catiónicos naturales, almidón de maíz y almidón de papa modificados; el primero con un grado de sustitución de 0,06, y el segundo, de 0,04. Después de la floculación, usaron centrifugación para cosechar la biomasa. Encontraron que para cosechar $9,1 \mathrm{~g}$ de biomasa se requirieron $2.41 \mathrm{~g}$ de almidón de papa modificado; para cosechar 
$12,9 \mathrm{~g}$ de biomasa se debieron usar $2,5 \mathrm{~g}$ de almidón de maíz modificado; $\mathrm{y}$, para cosechar $18 \mathrm{~g}$ de biomasa se usaron $12,3 \mathrm{~g}$ de alumbre. El artículo no presenta datos sobre eficiencia de floculación.

Otro trabajo de comparación de técnicas es el de Udhaya, Benedict y Sandhya (2014); este trabajo compara electro floculación y floculación química (con alumbre férrico a una dosificación de $160 \mathrm{mg} / \mathrm{L}$ ) para cosechar microalgas halotolerantes. Alcanzaron un 70\% de eficiencia con el alumbre, menor a la eficiencia alcanzada por la electrofloculación. Hansel, Riefler y Stuart (2014) publicaron los resultados de su evaluación de almidones modificados, con diferentes grados de sustitución, sobre la microalga Scenedesmus dimorphus. El grado de sustitución adecuado del almidón estaría entre 0,14 y 0,64. Otro trabajo sobre los almidones modificados fue el de Letelier-Gordo, Holdt, de Francisci, Karakashev y Angelidaki (2014), en el cual los autores usaron un almidón catiónico de tipo comercial (GreenFloc 120), variando la dosificación y el pH para flocular Chlorella protothecoides.

T'Lam et ál. (2014) probaron diferentes floculantes comerciales de base poliacrilamida, como Zetag 7557 y Synthofloc $5080 \mathrm{H}$, sobre las especies Phaeodactylum tricornutum y Neochloris oleoabundans, ambas microalgas marinas. Ninguno de los floculantes poliméricos aniónicos o no iónicos dio resultado positivo. Los catiónicos lograron eficiencias superiores al $98 \%$ con la primera especie, pero solo del $52 \%$ con la segunda. Posteriormente, T'Lam et ál. (2015) evaluaron las dosis efectivas de floculantes para la microalga Neochloris oleoabundans e incrementaron la eficiencia. Asimismo, obtuvieron un modelo matemático para relacionar la dosificación de floculante con la eficiencia para esta especie. Hamid et ál. (2014) compararon la eficiencia de derivados primarios, secundarios y terciarios de la semilla de Moringa oleifera, con respecto a sulfato de aluminio, para flocular ChloreIla sp. Los derivados terciarios, proteína posterior a la extracción del aceite de la harina, presentaron mejores eficiencias. König, Sales, Roselet y Abreu (2014) evaluaron cinco floculantes comerciales de tipo poliacrilamida catiónica para cosechar Conticribra weissflogii (un tipo de microalga marina) en diferentes fases de desarrollo celular; encontraron mejores resultados en la fase de crecimiento exponencial con Flopam FO4240 de densidad de carga baja, comparado con los demás floculantes usados.

Delrue, Imbert, Fleury, Peltier y Sassi (2015) compararon la efectividad de quitosano y diez agentes floculantes comerciales para concentrar Chlamydomonas reinhardtii, y encontraron mejores resultados con los floculantes comerciales basados en poliacrilamida catiónica. Gutiérrez, Passos, Ferrer, Uggetti y García (2015) presentaron los resultados de su evaluación de dos floculantes comerciales naturales, basados en taninos, para concentrar microalgas crecidas en lagunas de tratamiento de agua residual. Ainna et ál. (2015) compararon dos floculantes: cloruro férrico y AFlok (un floculante comercial de tipo biológico basado en el hongo Aspergillus niger), para concentrar microalgas que provenían de un estanque usado para acuicultura, cultivadas a condiciones naturales. El mejor resultado fue $98,7 \%$ de eficiencia con AFlok. Pérez, Cancela, Maceiras, Salgueiro y Sánchez (2015) evaluaron el procesado de Selenastrum Capricornutum, microalga de agua fresca, desde la coagulación-floculación hasta la extracción de lípidos. Como floculante emplearon sulfato cuproso a concentraciones de 0,5, 1 y $2 \mathrm{~g} / \mathrm{L}$; la dosificación de $2 \mathrm{~g} / \mathrm{L}$ alcanzó un $76 \%$. Otros estudios comparativos de floculantes, de ese año, fueron: Billuri, Bonner, Fuller e Islam (2015), investigación que comparó el almidón modificado con dos grados de sustitución diferentes (polímero catiónico sintético y quitosano) para flocular Chlorella protothecoides y Nannochloropsis salina; y Roselet, Vandamme, Roselet, Muylaert y Abreu (2015), estudio que comparó veinticinco polímeros naturales catiónicos comerciales para flocular Chlorella vulgaris y Nannochloropsis oculata. En cuanto a estudios comparativos de técnicas, Şirin, Clavero y Salvadó (2015) compararon la sedimentación por gravedad, la floculación inducida por pH y la floculación con sulfato de aluminio 
LÍNEA DE INVESTIGACIÓN: APROVECHAMIENTO DE RESIDUOS AGROINDUSTRIALES

y con cloruro de polialuminio para concentrar la biomasa de Chaetoceros calcitrans; los autores encontraron eficiencias similares con la floculación inducida y la floculación con las sales metálicas. Por su parte, Şirin y Sillanpää (2015) mostraron los beneficios de integrar el cultivo de microalga y la biorremediación, específicamente para tratamiento de aguas residuales urbanas; pero solamente evaluaron la sedimentación y la floculación inducida por pH para separar la biomasa.

Un avance reciente de la floculación es el uso de sustancias residuales como agentes floculantes. Un ejemplo de esto es el estudio de Salama et ál.(2015), que evaluó la posibilidad de usar drenaje ácido de minería, un líquido residual con iones de hierro (II y III), calcio, aluminio, sodio, magnesio, manganeso, potasio y sulfato. Igualmente, Lee y Choi (2015) probaron una mezcla de cloruro de magnesio y sericita (un agregado mineral) para flocular Chlorella vulgaris; los autores obtuvieron más del $99 \%$ de eficiencia, a pH entre 9 y 11. Seo, Park, Oh, Yoon y Han (2015) simularon aguas residuales provenientes del tratamiento de tintas, por medio de azul de metileno y naranja de metilo diluidos, y alcanzaron hasta un $90 \%$ de eficiencia de floculación.

En Colombia, Moreno, Muñoz y Casanova (2015) emplearon quitosano para flocular microalgas de agua fresca nativas del altiplano, Chlorella sp. y Scenedesmus sp. Los autores obtuvieron una eficiencia de $99,7 \%$ para Scenedesmus sp. y de 74,8\% para Chlorella sp. con 200 ppm de quitosano.

En lo que va corrido de este año, Chatsungnoen y Chisti (2016) comprobaron que la dosis efectiva (es decir, más del 95\% de eficiencia) para flocular Nannochloropsis salina, Neochlorosis sp., Chlorella minor y Chlorella vulgaris depende de la concentración inicial del cultivo. Emplearon floculantes tradicionales: sulfato de aluminio y cloruro férrico. Continuando con el trabajo de Roselet, Vandamme, Roselet, Muylaert y Abreu 2015), Roselet, Burkert y Abreu (2016) ensayaron nuevamente con el agente comercial Tanfloc para concentrar Nannochloropsis oculata, pero con el fin de evaluar la reproducibilidad de los resultados a escala planta piloto. Obtuvieron eficiencias de $98 \%$, cuando el pH era 6 y la salinidad $10 \mathrm{mg} / \mathrm{L}$. Baharuddin et ál. (2016) ensayaron harina de semillas de moringa después de extracción de aceite (MOAE, por sus siglas en inglés) y sin extracción de aceite (MOWE), para concentrar biomasa de Nannochloropsis oculata. Evaluaron el pH, el tiempo de sedimentación y la dosificación de floculante. Los mejores resultados se obtuvieron con MOAE a $5 \mathrm{~g} / \mathrm{L}$ de dosificación y $\mathrm{pH} 7$, con un $94 \%$ de eficiencia de remoción. Otro trabajo sobre el uso de la moringa, presentado por Hamid, Lananan, Khatoon y Endut (2016), muestra los resultados de su evaluación de los derivados primarios, secundarios y terciarios de la moringa, comparados con sulfato de aluminio para flocular y sedimentar Clorella sp. El trabajo más reciente de Endut, Hamid, Lananan y Kathoon (2016) usó las mismas sustancias floculantes e idéntica especie de microalga, y alcanzó eficiencias superiores a $97 \%$ con dosis desde $10 \mathrm{mg} / \mathrm{L}$ de floculante. Asimismo, en ese trabajo se propusieron modelos de ajuste para relacionar el $\mathrm{pH}$ con el potencial zeta, para diferentes suspensiones de Chlorella sp. con sulfato de aluminio y polvo de semilla y de proteína de Moringa oleífera.

Finalmente, el trabajo de Lecina, Nadal, Solà, Prat y Cairó (2016) presenta los resultados de su evaluación del efecto combinado del cloruro férrico y el pH sobre el crecimiento y floculación de Chlorella vulgaris. La microalga fue cultivada en un biorreactor en modo continuo, con recirculación del medio de cultivo, luego del cosechado con cloruro férrico. No observaron influencia significativa del $\mathrm{pH}$, pero sí de la dosificación del cloruro férrico. Este trabajo muestra la tendencia de las investigaciones actuales hacia la integración del proceso, con el fin de reducir costos y posibles efectos medioambientales. 


\section{Análisis de la información recopilada}

\section{Análisis de la producción de publicaciones}

En esta sección se presenta la distribución de publicaciones según fuente y año. Esto con el fin de tener una visión general de la información recopilada.

En la figura 1 se muestra el número de artículos según revista. Como se puede observar, la mayor fuente de información sobre el tema fue, sin duda, Bioresource Technology. No se incluyen en el gráfico las que han producido un solo artículo.

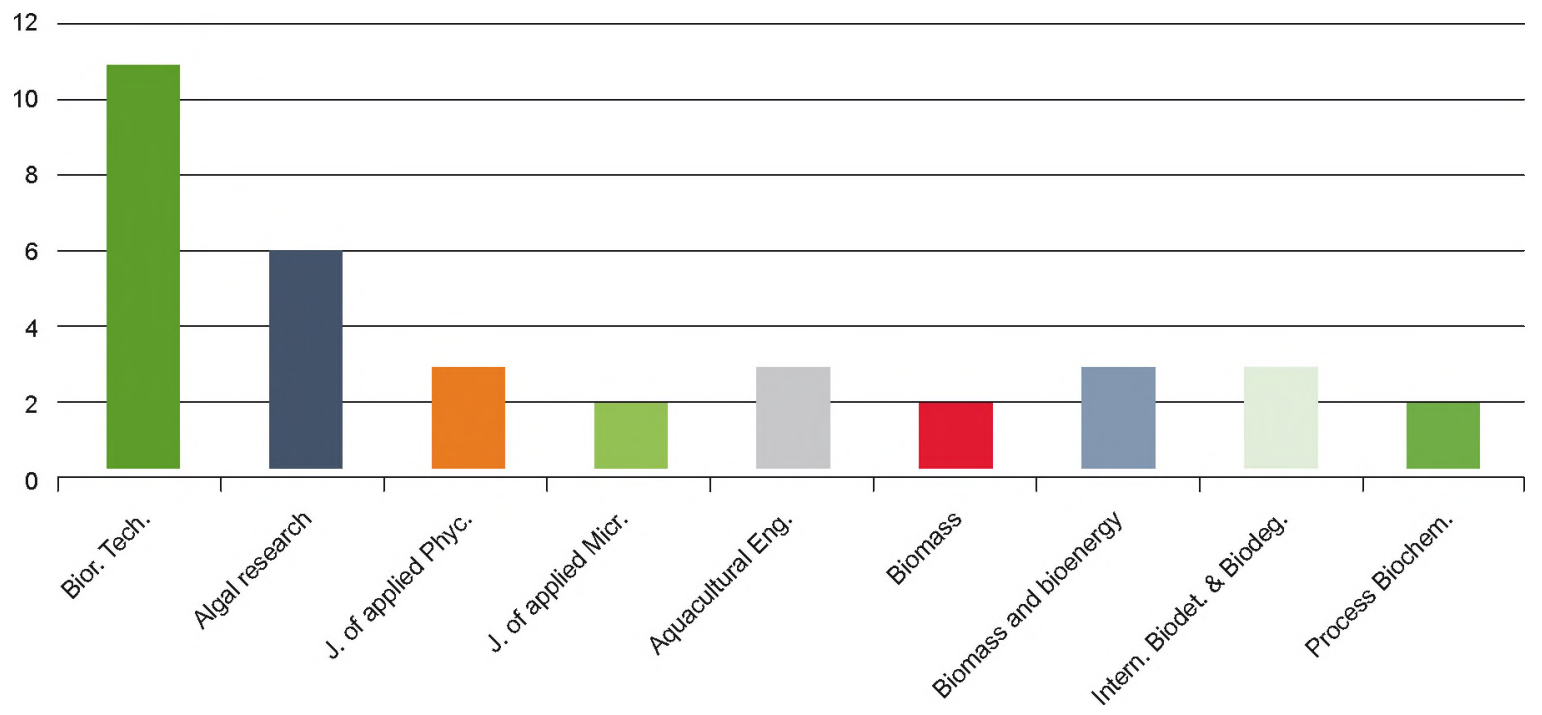

Figura 1. Distribución de publicaciones según revista.

La figura 2 muestra la evolución cronológica de las publicaciones sobre el tema y evidencia que el año 2013 fue el más prolífico en cuanto a número de artículos, tesis y revisiones publicadas, y que en lo que va corrido de 2016 (junio) existe una tendencia a superar la producción científica de 2015.

\section{Análisis de fondo de las publicaciones}

La tabla 1 presenta un resumen cronológico de las condiciones y de los resultados más significativos en remoción de biomasa, según la bibliografía estudiada.

La eficiencia de floculación se calculó, en la mayoría de los casos, por medio de la siguiente fórmula:

$$
\% E_{f}=\frac{O D_{750} \text { inicial }-O D_{750} \text { final }}{O D_{750} \text { inicial }} * 100 \%
$$

Donde $\mathrm{OD}_{750}$ corresponde a la densidad óptica de la muestra a una longitud de onda de $750 \mathrm{~nm}$. Se entiende que la densidad óptica es una medida directa de la concentración celular; así, a ma- 
yor densidad óptica, mayor concentración celular, y viceversa. El proceso de floculación variaba según los autores; pero en general cuenta con las siguientes etapas: agitación suave, adición del floculante, agitación fuerte por un breve período de tiempo para disolver el floculante y, finalmente, agitación larga y suave para permitir la sedimentación y separación. El tiempo posterior, en el que se tomaba la muestra variaba, algunos autores evaluaron resultados hasta cuatro horas después de la floculación.

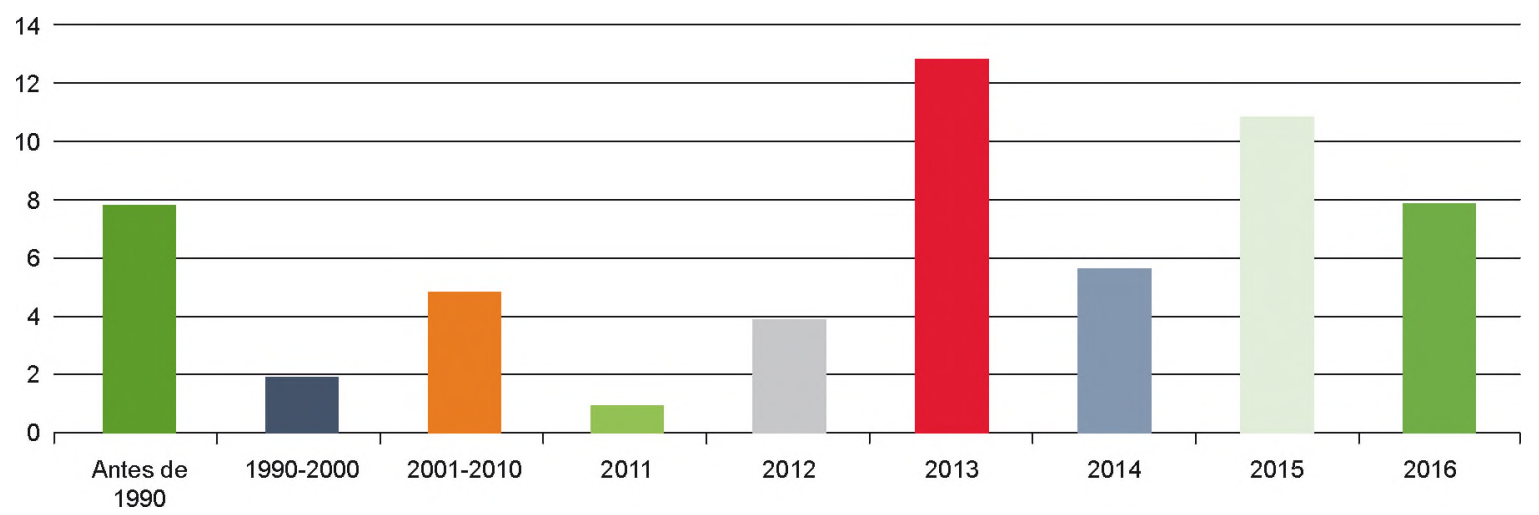

Figura 2. Evolución cronológica de publicaciones.

Tabla 1.

Resumen de técnicas y resultados en Floculación

\begin{tabular}{|c|c|c|c|c|}
\hline Floculante & Dosis & Condiciones & Resultados & Autor (es) \\
\hline Quitosano & $\begin{array}{l}40 \mathrm{mg} / \mathrm{L} \\
20 \mathrm{mg} / \mathrm{L}\end{array}$ & $\begin{array}{l}\mathrm{pH}: 7,8 \text { a } 8 \\
\mathrm{pH}: \text { menor a } 7\end{array}$ & $\begin{array}{l}100 \% \text { de } \\
\text { eficiencia de } \\
\text { remoción }\end{array}$ & $\begin{array}{l}\text { Morales, J., } \\
\text { de la Noüe, J. } \\
\text { y Picard, G. } \\
(1985)\end{array}$ \\
\hline $\begin{array}{l}\text { Quitosano } \\
\text { Zetag } 63 \\
\text { Zetag } 92\end{array}$ & $\begin{array}{l}5 \mathrm{mg} / \mathrm{L} \\
10 \mathrm{mg} / \mathrm{L} \\
7 \mathrm{mg} / \mathrm{L}\end{array}$ & $\mathrm{pH}: 7$ & $\begin{array}{l}90 \% \text { de eficiencia } \\
\text { de remoción }\end{array}$ & $\begin{array}{l}\text { Bilanovic, D., } \\
\text { Shelef, G. y } \\
\text { Sukenik, A. } \\
\text { (1988). }\end{array}$ \\
\hline Sulfato de aluminio & $200 \mathrm{mg} / \mathrm{L}$ & $\begin{array}{l}\mathrm{pH}: 11 \text { Botryococcus } \\
\text { braunii a } 2 \text { semanas } \\
\text { de incubación }\end{array}$ & $\begin{array}{l}90 \% \text { de eficiencia } \\
\text { de remoción }\end{array}$ & Lee et al. (2008) \\
\hline \multirow[t]{2}{*}{$\begin{array}{l}\mathrm{NaOH} \text { con Magnafloc } \\
\text { (polielectrolito) }\end{array}$} & $0,5 \mathrm{mg} / \mathrm{L}$ & $\mathrm{pH}: 10,2$ & $\begin{array}{l}\text { Hasta } 800 \text { veces } \\
\text { aumentó el factor } \\
\text { de concentración }\end{array}$ & $\begin{array}{l}\text { Knuckey, R., } \\
\text { Brown, M., } \\
\text { Robert, R. y } \\
\text { Frampton, D. } \\
(2009)\end{array}$ \\
\hline & & $\begin{array}{l}\mathrm{t}: 10 \min \mathrm{pH}: 11,5 \\
\text { sedimentación toda } \\
\text { la noche a } 4^{\circ} \mathrm{C}\end{array}$ & Hasta 700 veces & \\
\hline
\end{tabular}




\begin{tabular}{|c|c|c|c|c|}
\hline Floculante & Dosis & Condiciones & Resultados & Autor (es) \\
\hline $\mathrm{NaOH}$ solo & Hasta $0,5 \mathrm{mg} / \mathrm{L}$ & $\begin{array}{l}\mathrm{pH} 10 \text { Chaetoceros } \\
\text { calcitrans }\end{array}$ & $78 \%$ de eficiencia & \multirow{4}{*}{$\begin{array}{l}\text { Harith, Z., } \\
\text { Yussoff, F., } \\
\text { Mohamed, M., } \\
\text { Sharif, M., Din, } \\
\text { M. y Ariff, A. } \\
\text { (2009) }\end{array}$} \\
\hline $\begin{array}{l}\mathrm{NaOH} \text { con Magnafloc } \\
\text { (polielectrolito) }\end{array}$ & 0,1 a $1 \mathrm{mg} / \mathrm{L}$ & $\mathrm{pH} 10$ & $92 \%$ de eficiencia & \\
\hline Quitosano & $20 \mathrm{mg} / \mathrm{L}$ & $\mathrm{pH} 8$ & $83 \%$ de eficiencia & \\
\hline Quitosano & $20 \mathrm{mg} / \mathrm{L}$ & $\mathrm{pH} 9-10$ & $77 \%$ de eficiencia & \\
\hline Quitosano & $\begin{array}{l}\text { Diluido en ácido } \\
\text { acético, al 1\%. } 10 \\
\text { ppm }\end{array}$ & $\begin{array}{l}\mathrm{pH} \text { entre } 4 \text { y } 9, \\
\text { Chlorella vulgaris }\end{array}$ & $\begin{array}{l}99.3 \pm 0,7 \% \text { de } \\
\text { eficiencia } \\
{ }^{\star A} \text { d dosis mayores } \\
\text { a } 30 \mathrm{ppm} \text {, } \\
\text { disminuye }\end{array}$ & $\begin{array}{l}\text { Ahmad, A., } \\
\text { Yasin, N., Derek, } \\
\text { C. y Lim, J. } \\
(2010)\end{array}$ \\
\hline $\begin{array}{l}\text { Greenfloc } 120 \text { (Almidón } \\
\text { catiónico comercial de } \\
\text { grado de sustitución } \\
0,15 \text { ) }\end{array}$ & $\begin{array}{l}40 \mathrm{mg} / \mathrm{L} \\
30 \mathrm{mg} / \mathrm{L} \\
20 \mathrm{mg} / \mathrm{L}\end{array}$ & $\begin{array}{l}\text { Parachlorella } \\
\text { kessleri } 0,3 \mathrm{~g} / \mathrm{L} \text { de } \\
\text { biomasa } \\
0,15 \mathrm{~g} / \mathrm{L} \text { de biomasa } \\
0,05 \mathrm{~g} / \mathrm{L} \text { de biomasa }\end{array}$ & $\begin{array}{l}90 \% \text { de eficiencia } \\
\text { de remoción }\end{array}$ & $\begin{array}{l}\text { Vandamme, } \\
\text { D., Foubert, I., } \\
\text { Meesschaert, B. } \\
\text { y Muylaert, K. } \\
(2010)\end{array}$ \\
\hline $\begin{array}{l}\mathrm{Al} 2(\mathrm{SO} 4) 3, \\
\mathrm{AlCl} 3, \mathrm{Fe} 2(\mathrm{SO} 4) 3, \mathrm{FeCl} 3, \\
\mathrm{ZnSO} 4, \mathrm{ZnCl} 2, \mathrm{CaSO} 4, \\
\mathrm{CaCl} 2, \mathrm{MgSO} 4, \mathrm{MgCl} 2 \\
(\mathrm{NH} 4) 2 \mathrm{SO} 4, \text { and } \mathrm{NH} 4 \mathrm{Cl}\end{array}$ & $\begin{array}{l}0 \text { hasta } 5 \mathrm{~g} / \mathrm{L} \text { con } \\
\text { intervalos de } 0,5 \\
\mathrm{~g} / \mathrm{L}(12) \quad 0,25 \text { a } 1 \\
\mathrm{~g} / \mathrm{L} \text { con intervalos } \\
\text { de } 0,25 \mathrm{~g} / \mathrm{L}(6) \\
0 \text { a } 1,5 \mathrm{~g} / \mathrm{L} \text { con } \\
\text { intervalos de } 0,1 \\
\mathrm{~g} / \mathrm{L} \text { ( } 3 \text { mejores) }\end{array}$ & $\begin{array}{l}\text { *Los mejores } \\
\text { resultados fueron } \\
\text { sales de cloruros y } \\
\text { sales de aluminio. } \\
\text { Chlorella } \\
\text { minutissima }\end{array}$ & $\begin{array}{l}\text { Más de } 90 \% \\
\text { de eficiencia de } \\
\text { coagulación luego } \\
\text { de } 2 \text { horas de } \\
\text { incubación, con } \\
\text { AlCl3 a } 0,5 \mathrm{~g} / \mathrm{L}\end{array}$ & $\begin{array}{l}\text { Papazi, A., } \\
\text { Makridis, P. } \\
\text { Divanac, P. } \\
(2010)\end{array}$ \\
\hline Quitosano & $0-0,69 \mathrm{mg} / \mathrm{L}$ & $\begin{array}{l}\mathrm{pH}: 5,5 ; 7 \text { y } 8,5 \\
\text { Chlorella vairabilis } \\
\text { NC64A }\end{array}$ & $\begin{array}{l}\text { Depende de } \\
\text { composición de la } \\
\text { pared celular }\end{array}$ & $\begin{array}{l}\text { Cheng, Y., } \\
\text { Zheng, Y., } \\
\text { Labavitch, J. y } \\
\text { Vandergheynst, } \\
\text { J. (2011) }\end{array}$ \\
\hline $\mathrm{Ca}(\mathrm{OH}) 2$ & $0,15 \mathrm{mg} / \mathrm{L}$ & $\begin{array}{l}\text { Nannochloropsis sp, } \\
\mathrm{pH}: 10\end{array}$ & $97 \%$ de eficiencia & $\begin{array}{l}\text { Schlesinger et } \\
\text { al. (2012) }\end{array}$ \\
\hline $\begin{array}{l}\text { Harina de semillas de } \\
\text { Moringa oleifera }\end{array}$ & $1 \mathrm{~g} / \mathrm{L}$ & Chlorella vulgaris. & $\begin{array}{l}96 \% \text { de eficiencia } \\
\text { de remoción } \\
\text { para Tiempo de } \\
\text { sedimentación } 4 \\
\text { horas. } \\
80 \% \text { de eficiencia } \\
\text { de remoción } \\
\text { para Tiempo de } \\
\text { sedimentación } 2 \\
\text { horas }\end{array}$ & $\begin{array}{l}\text { Lapa Teixeira, } \\
\text { C., Kirsten, F. } \\
\text { y Teixeira, P. } \\
(2012)\end{array}$ \\
\hline
\end{tabular}


LÍNEA DE INVESTIGACIÓN: APROVECHAMIENTO DE RESIDUOS AGROINDUSTRIALES

\begin{tabular}{|c|c|c|c|c|}
\hline Floculante & Dosis & Condiciones & Resultados & Autor (es) \\
\hline Polielectrolito EM1 & $15 \mathrm{mg} / \mathrm{L}$ & \multirow{7}{*}{$\begin{array}{l}\text { En todos los casos } \\
\text { la concentración } \\
\text { inicial de la biomasa } \\
\text { fue } 2 \text { g/L. El tiempo } \\
\text { de floculación } \\
\text { fue } 15 \text { minutos. } \\
\text { Muriellopsis sp.; } \\
\text { Chlorella vulgaris; } \\
\text { Chlorella fusca; } \\
\text { Scenedesmus } \\
\text { suspicatus; } \\
\text { Scenedesmus sp. }\end{array}$} & $\begin{array}{l}\text { Factor de } \\
\text { concentración: } 37\end{array}$ & \\
\hline Polielectrolito EM16 & $10 \mathrm{mg} / \mathrm{L}$ & & $\begin{array}{l}\text { Factor de conc: } \\
26\end{array}$ & \\
\hline Polielectrolito EM22 & $16 \mathrm{mg} / \mathrm{L}$ & & $\begin{array}{l}\text { Factor de conc: } \\
37\end{array}$ & $\begin{array}{l}\text { Granados, } \\
\text { M., Acien, G., } \\
\text { Gómez, C., } \\
\text { Fernández- } \\
\text { Sevilla, J. y } \\
\text { Molina Grima, E. } \\
\text { (2012) }\end{array}$ \\
\hline Polielectrolito FB1 & $12 \mathrm{mg} / \mathrm{L}$ & & $\begin{array}{l}\text { Factor de conc: } \\
36\end{array}$ & \\
\hline Polielectrolito EM1 & $8 \mathrm{mg} / \mathrm{L}$ & & $\begin{array}{l}\text { Factor de conc: } \\
37\end{array}$ & \\
\hline Polielectrolito FB1 & $3 \mathrm{mg} / \mathrm{L}$ & & $\begin{array}{l}\text { Factor de conc: } \\
36\end{array}$ & \\
\hline Polielectrolito EM22 & $25 \mathrm{mg} / \mathrm{L}$ & & $\begin{array}{l}\text { Factor de } \\
\text { concentración: } 38\end{array}$ & \\
\hline \multirow{2}{*}{ Ácido alfa glutámico } & $22,03 \mathrm{mg} / \mathrm{L}$ & $\begin{array}{l}0,57 \mathrm{~g} / \mathrm{L} \text { células; } \\
11,56 \mathrm{~g} / \mathrm{L} \text { sal. } \\
\text { Chlorella Vulgaris. T: } \\
2 \text { horas }\end{array}$ & $\begin{array}{l}91 \% \text { de eficiencia } \\
\text { y factor de } \\
\text { concentración } 21\end{array}$ & \multirow[b]{2}{*}{$\begin{array}{l}\text { Zheng et al. } \\
(2012)\end{array}$} \\
\hline & $19,82 \mathrm{mg} / \mathrm{L}$ & $\begin{array}{l}0,57 \mathrm{~g} / \mathrm{L} \text { cél; } 11,56 \\
\mathrm{~g} / \mathrm{L} \text { sal. Chlorella } \\
\text { Protothecoides. } \\
\mathrm{T}: 2 \text { horas }\end{array}$ & $\begin{array}{l}98 \% \text { de eficiencia } \\
\text { y factor de } \\
\text { concentración } 30\end{array}$ & \\
\hline Sulfato de aluminio & Desde 50 ppm & $\begin{array}{l}\text { Schizochytrium } \\
\text { limacinum, } \\
\text { concentración } 0,93 \\
\mathrm{~g} / \mathrm{L} \text { y } 4,65 \mathrm{~g} / \mathrm{L}\end{array}$ & $\begin{array}{l}\text { Más del } 90 \% \text { de } \\
\text { eficiencia }\end{array}$ & \multirow{3}{*}{$\begin{array}{l}\text { Gerde, J., Yao, } \\
\text { L., Lio, J., Wen, } \\
\text { Z. y Wang, T. } \\
\text { (2013) }\end{array}$} \\
\hline Almidón modificado 05 & 25 ppm & $\begin{array}{l}\text { Chlamydomonas } \\
\text { reinhardtii } 0,31 \mathrm{~g} / \mathrm{L}\end{array}$ & $\begin{array}{l}\text { Más del } 90 \% \text { de } \\
\text { eficiencia }\end{array}$ & \\
\hline Almidón modificado 02 & 60 ppm & $\begin{array}{l}\text { Scenedesmus sp, } \\
1 \mathrm{~g} / \mathrm{L}\end{array}$ & $90 \%$ de eficiencia & \\
\hline Quitosano & $0,12 \mathrm{~g} / \mathrm{L}$ & $\begin{array}{l}\mathrm{pH}: 6 . \text { Chlorella } \\
\text { vulgaris }\end{array}$ & $\begin{array}{l}\text { Mayor a } 99 \% \text {, } \\
\text { factor de } \\
\text { concentración de } \\
10\end{array}$ & $\begin{array}{l}\text { Rashid, N., } \\
\text { Rehman, S. y } \\
\text { Han, J. (2013) }\end{array}$ \\
\hline Almidón de papa & $2,41 \mathrm{~g}$ & $\begin{array}{l}0,41 \mathrm{~g} \text { de } \\
\text { Scenedesmus } \\
\text { Obliquus }\end{array}$ & $\begin{array}{l}\text { NO EVALUARON } \\
\text { LA EFICIENCIA. }\end{array}$ & $\begin{array}{l}\text { Anthony et al. } \\
(2013)\end{array}$ \\
\hline
\end{tabular}




\begin{tabular}{|c|c|c|c|c|}
\hline Floculante & Dosis & Condiciones & Resultados & Autor (es) \\
\hline $\mathrm{FeCl} 3$ & $0,2 \mathrm{~g} / \mathrm{L}$ & & & \\
\hline $\mathrm{Al} 2(\mathrm{SO} 4) 3$ & $0,3 \mathrm{~g} / \mathrm{L}$ & Soenedeamus on & Mayor a $95 \%$ & Chen, L., Wang, \\
\hline Alumbre & $0,3 \mathrm{~g} / \mathrm{L}$ & scenedesmus sp. & en menos de 10 & $\begin{array}{l}\text { C., wang, w. y } \\
\text { Wei J (2013) }\end{array}$ \\
\hline Quitosano & $0,1 \mathrm{~g} / \mathrm{L}$ & & & \\
\hline $\begin{array}{l}\text { Quitosano en ácido } \\
\text { cítrico }\end{array}$ & \multirow{4}{*}{$\begin{array}{l}30 \mathrm{mg} / \mathrm{L} \text { de } \\
\text { solución } 0,1 \mathrm{M}\end{array}$} & Chlorella vulgaris & $5,5 \%$ de eficiencia & \multirow{4}{*}{$\begin{array}{l}\text { Rashid, N., } \\
\text { Rehman, S. y } \\
\text { Han, J. }(2013, \text { b) }\end{array}$} \\
\hline Quitosano en $\mathrm{HNO} 3$ & & Chlorella vulgaris & $55 \%$ de eficiencia & \\
\hline Quitosano en $\mathrm{H} 3 \mathrm{PO} 4$ & & Chlorella vulgaris & $69 \%$ de eficiencia & \\
\hline Quitosano en $\mathrm{HCl}$ & & Chlorella vulgaris & $85 \%$ de eficiencia & \\
\hline Quitosano & $\begin{array}{l}2,78 \mathrm{~kg} / \mathrm{kg} \\
\text { biomasa seca }\end{array}$ & $\begin{array}{l}\text { pH: 9; Picochlorum } \\
\text { oklahomensis }\end{array}$ & $\begin{array}{l}98,4 \% \text { de } \\
\text { eficiencia }\end{array}$ & $\begin{array}{l}\text { Zhu Y., Dunford, } \\
\text { T. y Goad, C. } \\
\text { (2013) }\end{array}$ \\
\hline Alumbre férrico & $160 \mathrm{mg} / \mathrm{L}$ & $\begin{array}{l}\mathrm{pH}: 7,8 . \text { Chlorella } \\
\text { vulgaris }\end{array}$ & $70 \%$ de eficiencia & $\begin{array}{l}\text { Udhaya, R., } \\
\text { Benedict, L. y } \\
\text { Sandhya, S. } \\
(2014) .\end{array}$ \\
\hline $\begin{array}{l}\text { Almidón catiónico } \\
\text { (diferentes tipos: de } \\
\text { papa, de maíz, entre } \\
\text { otros) }\end{array}$ & $10 \mathrm{mg} / \mathrm{L}$ & $\begin{array}{l}\text { Scenedesmus } \\
\text { dimorphus. } \mathrm{pH}: 7\end{array}$ & $\begin{array}{l}\text { Mayor a } 97 \% \\
\text { de eficiencia. } \\
\text { Disminuye } \\
\text { a mayor } \\
\text { dosificación. }\end{array}$ & $\begin{array}{l}\text { Hansel, P., } \\
\text { Riefler, G. y } \\
\text { Stuart, B. (2014). }\end{array}$ \\
\hline Greenfloc 120 & $40 \mathrm{mg} / \mathrm{l}$ & $\begin{array}{l}\text { Densidades } \\
\text { de medio entre } \\
0,44 \text { y } 0,77 \mathrm{~g} / \mathrm{L} \text {. } \\
\text { pH } 7,7 \text {. Chlorella } \\
\text { protothecoides }\end{array}$ & $\begin{array}{l}90 \% \text { de eficiencia } \\
\text { de remoción, } \\
\text { máximo }\end{array}$ & $\begin{array}{l}\text { Letelier-Gordo, } \\
\text { C., Holdt, S., De } \\
\text { Francisci, D., } \\
\text { Karakashev, D. } \\
\text { y Angelidaki, I. } \\
\text { (2014) }\end{array}$ \\
\hline Zetag 7557 & $0,01 \mathrm{mg} / \mathrm{L}$ & $\begin{array}{l}\text { Neochloris } \\
\text { oleoabundans, } \mathrm{pH} \text { : } \\
7,5\end{array}$ & $52 \%$ de eficiencia & \multirow{2}{*}{$\begin{array}{l}\text { T'Lam et al. } \\
\text { (2014) }\end{array}$} \\
\hline $\begin{array}{l}\text { Zetag } 7557 \text {, Synthofloc } \\
5080 \mathrm{H} \text { y SNF H536 }\end{array}$ & $0,01 \mathrm{mg} / \mathrm{L}$ & $\begin{array}{l}\text { Phaeodactylum } \\
\text { tricornutum, } \mathrm{pH}: 7,5\end{array}$ & $98 \%$ de eficiencia & \\
\hline $\begin{array}{l}\text { Harina de semillas de } \\
\text { Moringa oleífera }\end{array}$ & $10 \mathrm{mg} / \mathrm{L}$ & $\mathrm{pH}$ : 7. Chlorella sp. & $\begin{array}{l}\text { Mayor a } 97 \% \text { de } \\
\text { eficiencia }\end{array}$ & $\begin{array}{l}\text { Hamid et al. } \\
(2014)\end{array}$ \\
\hline FLOPAM® FO $4240 \mathrm{SH}$ & $\begin{array}{l}0,002-0,004 \\
\mathrm{mg} / \mathrm{L}\end{array}$ & $\begin{array}{l}\text { Conticribra } \\
\text { weissflogii, }\end{array}$ & $\begin{array}{l}\text { Mayor a } 90 \% \text { de } \\
\text { eficiencia }\end{array}$ & $\begin{array}{l}\text { König, R., Sales, } \\
\text { R., Roselet, F.y } \\
\text { Abreu, P. (2014) }\end{array}$ \\
\hline $\begin{array}{l}\text { Clorosulfato de } \\
\text { polialuminio }\end{array}$ & $\begin{array}{l}39,7 \mathrm{~g} / \mathrm{Kg} \text { de } \\
\text { biomasa seca }\end{array}$ & \multirow{3}{*}{$\begin{array}{l}\text { Chlamydomonas } \\
\text { reinhardtii, } \\
\text { concentración del } \\
\text { cultivo: } 0,65 \mathrm{~g} / \mathrm{L}\end{array}$} & $90 \%$ de eficiencia & \multirow{3}{*}{$\begin{array}{l}\text { Delrue, F., } \\
\text { Imbert, Y., } \\
\text { Fleury, G., } \\
\text { Peltier, G. y } \\
\text { Sassi, J. (2015) }\end{array}$} \\
\hline Quitosano & $\begin{array}{l}35 \mathrm{~g} / \mathrm{Kg} \text { de } \\
\text { biomasa seca }\end{array}$ & & $93 \%$ de eficiencia & \\
\hline Poliacrilamida catiónica & $\begin{array}{l}97 \mathrm{~g} / \mathrm{Kg} \text { de } \\
\text { biomasa seca }\end{array}$ & & $97 \%$ de eficiencia & \\
\hline
\end{tabular}


LÍNEA DE INVESTIGACIÓN: APROVECHAMIENTO DE RESIDUOS AGROINDUSTRIALES

\begin{tabular}{|c|c|c|c|c|}
\hline Floculante & Dosis & Condiciones & Resultados & Autor (es) \\
\hline Ecotan & $40 \mathrm{mg} / \mathrm{L}$ & $\begin{array}{l}\mathrm{pH}: 6,9 \text { Microalga } \\
\text { de laguna de } \\
\text { tratamiento de agua } \\
\text { residual }\end{array}$ & $\begin{array}{l}99,8 \% \text { de } \\
\text { eficiencia }\end{array}$ & $\begin{array}{l}\text { Gutiérrez, } \\
\text { R., Passos, } \\
\text { F., Ferrer, I., }\end{array}$ \\
\hline Tanfloc & $60 \mathrm{mg} / \mathrm{L}$ & $\mathrm{pH}: 7,7$ & $\begin{array}{l}93,3 \% \text { de } \\
\text { eficiencia }\end{array}$ & García, J. (2015) \\
\hline Aflok & & Mezcla de especies & $\begin{array}{l}98,7 \% \text { de } \\
\text { eficiencia }\end{array}$ & $\begin{array}{l}\text { Ainna et al. } \\
(2015)\end{array}$ \\
\hline Sulfato de cobre (II) & $2 \mathrm{~g} / \mathrm{L}$ & $\begin{array}{l}120 \text { minutos de } \\
\text { sedimentación. } \\
\text { Selenastrum } \\
\text { Tricornutum }\end{array}$ & $76 \%$ de eficiencia & $\begin{array}{l}\text { Pérez, L., } \\
\text { Cancela, A., } \\
\text { Maceiras, R., } \\
\text { Salgueiro, J. } \\
\text { y Sánchez, J. } \\
(2015) .\end{array}$ \\
\hline Quitosano & $40 \mathrm{mg} / \mathrm{L}$ & $\begin{array}{l}\mathrm{pH}: 7 \text {; concentración } \\
\text { biomasa } 1 \mathrm{~g} \text { (seco) } \\
\text { /L Chlorella vulgaris }\end{array}$ & $99 \%$ de eficiencia & $\begin{array}{l}\text { Moreno, L., } \\
\text { Muñoz, E. y } \\
\text { Casanova, H. } \\
\text { (2015). }\end{array}$ \\
\hline Mg-Sericita & $\begin{array}{l}\text { Relación Mg/S : } \\
40\end{array}$ & $\begin{array}{l}\mathrm{pH}: 9 \text { - } 11 ; \\
\text { concentración } \\
\text { biomasa: } 2,13 \mathrm{mg} / \mathrm{L} \\
\text { Chlorella vulgaris }\end{array}$ & $\begin{array}{l}\text { Más del } 99 \% \text { de } \\
\text { eficiencia. }\end{array}$ & $\begin{array}{l}\text { Lee, S. y Choi, } \\
\text { H.(2015) }\end{array}$ \\
\hline Policloruro de aluminio & $30 \mathrm{ppm}$ & $\begin{array}{l}\text { Phaeodactylum } \\
\text { tricornutum } \mathrm{pH}: 7,5\end{array}$ & $87 \%$ de eficiencia & $\begin{array}{l}\text { Sirin, S., } \\
\text { Clavero, E. }\end{array}$ \\
\hline Sulfato de aluminio & 10 ppm & $\begin{array}{l}\mathrm{pH}: 5,930 \mathrm{~min} \\
\text { sedimentación }\end{array}$ & $90 \%$ de eficiencia & $\begin{array}{l}\text { y Salvadó, J. } \\
\text { (2015) }\end{array}$ \\
\hline Zetag 7557 y SNF H536 & $\begin{array}{l}43-109 \mathrm{mg} \\
\text { floc./g biomasa }\end{array}$ & $\begin{array}{l}\text { Neochloris } \\
\text { oleoabundans }\end{array}$ & $99 \%$ de eficiencia & $\begin{array}{l}\text { T'Lam et al. } \\
(2015)\end{array}$ \\
\hline Drenaje ácido de minería & $\begin{array}{l}10 \% \text { en volumen a } \\
\mathrm{pH} 7 \text { y } \mathrm{pH} 9\end{array}$ & $\begin{array}{l}\text { Scenedesmus } \\
\text { obliquus y Chlorella } \\
\text { vulgaris }\end{array}$ & $\begin{array}{l}78 \text { - } 80 \% \text { de } \\
\text { eficiencia para } \\
\text { concentración } \\
\text { inicial de } 0,5 \mathrm{~g} / \mathrm{L} \mathrm{y} \\
1 \mathrm{~g} / \mathrm{L} \text { de biomasa. }\end{array}$ & $\begin{array}{l}\text { Salama et al. } \\
(2015)\end{array}$ \\
\hline Almidón catiónico $(0,5)$ & $0,02 \mathrm{~g} / \mathrm{g}$ alga & $\begin{array}{l}\text { Chlorella } \\
\text { protothecoides y }\end{array}$ & $\begin{array}{l}95 \% \text { de eficiencia } \\
\text { para } 0,5 \mathrm{~g} / \mathrm{L} \text { de } \\
\text { biomasa }\end{array}$ & $\begin{array}{l}\text { Billuri, M., } \\
\text { Bonner, J., }\end{array}$ \\
\hline Quitosano & seca & $\begin{array}{l}\text { Nannochloropsis } \\
\text { salina. } \mathrm{pH} 6\end{array}$ & $\begin{array}{l}98 \% \text { de eficiencia } \\
\text { para } 0,95 \mathrm{~g} / \mathrm{L} \text { de } \\
\text { biomasa }\end{array}$ & $\begin{array}{l}\text { Fuller, Ch. y } \\
\text { Islam, M. (2015) }\end{array}$ \\
\hline
\end{tabular}




\begin{tabular}{|c|c|c|c|c|}
\hline Floculante & Dosis & Condiciones & Resultados & Autor (es) \\
\hline \multirow[t]{2}{*}{ Flopam FO $4550 \mathrm{SH}$} & $0,55 \mathrm{mg} / \mathrm{l}$ & $\begin{array}{l}\text { Nannochloropsis } \\
\text { oculata }(290 \mathrm{mg} / \mathrm{L} \\
\text { biomasa) }\end{array}$ & $67 \%$ de eficiencia & \multirow{6}{*}{$\begin{array}{l}\text { Roselet, F., } \\
\text { Vandamme, D., } \\
\text { Roselet, M., } \\
\text { Muylaert, K. y } \\
\text { Abreu, P. (2015) }\end{array}$} \\
\hline & $1,66 \mathrm{mg} / \mathrm{L}$ & $\begin{array}{l}\text { Chlorella vulgaris } \\
\text { ( } 260 \mathrm{mg} / \mathrm{L} \text { biomasa) }\end{array}$ & $100 \%$ & \\
\hline \multirow{2}{*}{ Flopam FO $4990 \mathrm{SH}$} & $0,55 \mathrm{mg} / \mathrm{L}$ & $\begin{array}{l}\text { Nannochloropsis } \\
\text { oculata ( } 290 \mathrm{mg} / \mathrm{L} \\
\text { biomasa) }\end{array}$ & $90 \%$ & \\
\hline & $1,66 \mathrm{mg} / \mathrm{L}$ & $\begin{array}{l}\text { Chlorella vulgaris } \\
\text { (260 mg/L biomasa) }\end{array}$ & $99 \%$ & \\
\hline \multirow[t]{2}{*}{ Zetag 8185} & $0,55 \mathrm{mg} / \mathrm{L}$ & $\begin{array}{l}\text { Nannochloropsis } \\
\text { oculata }(290 \mathrm{mg} / \mathrm{L} \\
\text { biomasa) }\end{array}$ & $75 \%$ & \\
\hline & $5 \mathrm{mg} / \mathrm{L}$ & $\begin{array}{l}\text { Chlorella vulgaris } \\
\text { (260 mg/L biomasa) }\end{array}$ & $100 \%$ & \\
\hline \multirow[t]{2}{*}{ Tanfloc } & $5 \mathrm{mg} / \mathrm{L}$ & $\begin{array}{l}\text { Nannochloropsis } \\
\text { oculata ( } 290 \mathrm{mg} / \mathrm{L} \\
\text { biomasa) }\end{array}$ & $97 \%$ & \\
\hline & $5 \mathrm{mg} / \mathrm{L}$ & $\begin{array}{l}\text { Chlorella vulgaris } \\
\text { ( } 260 \mathrm{mg} / \mathrm{L} \text { biomasa) }\end{array}$ & $100 \%$ & \\
\hline $\begin{array}{l}\text { Agua residual de tintas } \\
\text { oxidadas (azul de } \\
\text { metileno y naranja de } \\
\text { metilo) }\end{array}$ & $20 \mathrm{mg} / \mathrm{L}$ & Chlorella sp. & $\begin{array}{l}>90 \% \text { de } \\
\text { eficiencia }\end{array}$ & $\begin{array}{l}\text { Seo, Y., Park, D., } \\
\text { Oh, y., Yoon, S. y } \\
\text { Han, J. (2015) }\end{array}$ \\
\hline $\begin{array}{l}\text { Sulfato de aluminio } \\
\text { Cloruro férrico }\end{array}$ & \multicolumn{3}{|c|}{$\begin{array}{l}\text { No aplica, porque el estudio fue muy amplio, con el fin de } \\
\text { encontrar una correlación entre dosis efectiva de floculante } \\
\text { para obtener } 95 \% \text { de eficiencia y factores como tamaño } \\
\text { medio de célula y concentración inicial de biomasa. }\end{array}$} & $\begin{array}{l}\text { Chatsungnoen, } \\
\text { T. y Chisti, Y. } \\
\text { (2016) }\end{array}$ \\
\hline Tanfloc & Escala piloto & $\begin{array}{l}\text { Nannochloropsis } \\
\text { oculata }\end{array}$ & $98 \%$ de eficiencia & $\begin{array}{l}\text { Roselet, F., } \\
\text { Burkert, J. y } \\
\text { Abreu, P. (2016) }\end{array}$ \\
\hline $\begin{array}{l}\text { Harina de semillas de } \\
\text { Moringa oleífera }\end{array}$ & $5 \mathrm{~g} / \mathrm{L}$ & $\begin{array}{l}\text { Nannochloropsis } \\
\text { oculata } \\
\text { pH } 7120 \text { minutos de } \\
\text { sedimentación }\end{array}$ & $\begin{array}{l}>90 \% \text { de } \\
\text { eficiencia }\end{array}$ & $\begin{array}{l}\text { Baharuddin et } \\
\text { al. (2016) }\end{array}$ \\
\hline $\begin{array}{l}\text { Polvo de harina de } \\
\text { semillas de Moringa } \\
\text { oleífera }\end{array}$ & $10 \mathrm{mg} / \mathrm{L}$ & Chlorella sp & $\begin{array}{l}97 \% \text { de eficiencia } \\
\text { de remoción }\end{array}$ & $\begin{array}{l}\text { Endut, A., } \\
\text { Hamid, S., } \\
\text { Lananan, F. y } \\
\text { Kathoon, H. } \\
\text { (2016) }\end{array}$ \\
\hline
\end{tabular}

Fuente: elaboración propia

La tabla 2 muestra la clasificación de los trabajos analizados según la especie de microalga estudiada. Se indica solamente el (los) floculante (s) estudiado (s) en cada caso. Como se puede observar, la especie a la que más atención se le ha dedicado es Chlorella vulgaris. Asimismo, el 
LÍNEA DE INVESTIGACIÓN: APROVECHAMIENTO DE RESIDUOS AGROINDUSTRIALES

quitosano se ha empleado para diversidad de especies de microalgas, tanto marinas como de agua fresca, siendo mejores sus resultados en ese último caso. Para microalgas marinas predomina el uso de electrolitos, como alumbre, policloruros y sulfatos de aluminio y de cobre, entre otros. Los almidones modificados se han empleado tanto para microalgas marinas como para las de agua fresca; sin embargo, han dado mejores resultados para algas de agua fresca. También destaca el uso de derivados de Moringa oleífera.

Tabla 2.

Clasificación de los artículos obtenidos según especie de microalga

\begin{tabular}{ll}
\hline \multicolumn{1}{c}{ Especie } & \multicolumn{1}{c}{ Floculantes } \\
\hline Botryococcus braunii & Sulfato de aluminio \\
Chaetoceros calcitrans & NaOH, NaOH con Magnafloc (polielectrolito) y Quitosano \\
Chlamydomonas reinhardtii & Almidón modificado 05, Alumbre férrico, Clorosulfato de polialuminio, \\
& Quitosano, Poliacrilamida catiónica \\
Chlorella minutissima & Sulfatos y cloruros de aluminio, magnesio, hierro, calcio y zinc \\
Chlorella Protothecoides & Ácido alfa glutámico, Greenfloc 120 y Quitosano, almidón catiónico 0,5 \\
Chlorella sp. & Agua residual de tintas oxidadas (azul de metileno y naranja de metilo) y \\
Chlorella variabilis NC64A & Polvo de semillas de Moringa oleífera \\
& Quitosano \\
Chlorella vulgaris & Quitosano, derivados de Moringa, ácido alfa glutámico, polielectrolitos, \\
& alumbre férrico, Mg-Sericita, Tanfloc, Drenaje ácido de minería, Flopam \\
Conticribra weissflogii & FO 4550 SH, Flopam FO 4990 SH y Zetag 8185 \\
Nannochloropsis oculata & FLOPAM ${ }^{\circ}$ FO 4240 SH \\
Nannochloropsis salina & Tanfloc, Flopam FO 4550 SH, Flopam FO 4990 SH y Zetag 8185 y \\
Nannochloropsis sp. & Quitosano, almidón catiónico 0,5 \\
Neochloris oleoabundans & Ca(OH)2 \\
Parachlorella kessleri & Zetag 7557, Harina de semillas de moringa \\
Phaeodactylum tricornutum & Greenfloc 120 \\
Picochlorum oklahomensis & Policloruro de aluminio, Sulfato de aluminio, Quitosano, Zetag 7557, \\
Scenedesmus sp. & Synthofloc 5080H y SNF H536 y Harina de semillas de moringa \\
Scenedesmus spp. & Quitosano \\
Schizochytrium limacinum & FeCl3, Al2(SO4)3, Alumbre y Quitosano \\
Selenastrum Tricornutum & Sulfato de aluminio \\
Mezcla de especies & Ecotan, Tanfloc, Aflok \\
\hline &
\end{tabular}

Fuente: elaboración propia 


\section{CONCLUSIONES}

El estado del arte de la floculación química para concentrar microalgas ha evolucionado desde el uso de floculantes asociados al tratamiento de aguas residuales, hasta sofisticadas composiciones de mezclas entre polímeros orgánicos y sales minerales o, incluso, biofloculantes mezclados con metales, pasando por compuestos naturales derivados de plantas.

El estudio de la floculación no solamente está enfocado a encontrar las sustancias que permitan obtener los mejores resultados en cuanto a porcentaje de eficiencia o tiempo de floculación y sedimentación, sino que además incluye el análisis del efecto que puedan tener variables como el pH, el potencial zeta, la presencia de materia orgánica en el medio, la forma de preparar el floculante o la combinación de métodos sobre los resultados mismos de la floculación y, más aún, en etapas posteriores del procesado, pensando en que los productos finales tengan la más alta calidad y todo el proceso sea sostenible económica y ambientalmente.

Las perspectivas del tema son amplias y buscan mejorar la eficiencia del proceso y reducir costos, para que los productos finales, especialmente el biodiesel, sean competitivos. Una de las líneas de futuras investigaciones es la integración de procesos, posiblemente cosechar en el mismo reactor de cultivo, reciclando el medio de cultivo. También la extracción directa sin cosechado previo. Sin embargo, continúan estudiándose las mejores condiciones con floculantes que han sido ampliamente usados, pero en los que aún se puede optimizar su uso.

\section{REFERENCIAS}

Ahmad, A., Yasin, N., Derek, C., y Lim, J. (2010). Coagulation-flocculation Process to Enhance Microfiltration of Separation Microalgae/culture medium. En Wawan Gunawan A. Kadir, $8^{a}$ Conferencia Internacional en Ciencia y Tecnología de Membranas. Facultad de Tecnología Industrial, Bandung, Indonesia.

Ainna, T., Amar, M., Omar, H., y Ismail, A. (2015). Flocculation of Mixed Microalgae using Ferric (III) Chloride and Aspergillus-based Flocculant. En Seminario de Ecología de Malasia. Departamento de Biología, Facultad de Ciencia, Universidad Putra Malaysi, Putrajaya, Malasia.

Anthony, R., Ellis, J., Sathish, A., Rahman, A., Miller, C, y Sims, R. (2013). Effect of coagulant/flocculants on bioproducts from microalgae. Bioresource Technology, 149, 65-70.

Baharuddin, N., Aziz, N., Sohif, H., Karim, W., Al-Obaidi, J., y Basiran, M. (2016). Marine Microalgae flocculation using plant: the case of Nannochloropsis Oculata and Moringa Oleifera. Pakistan Journal of Botany, 48(2), 831-842.

Beuckels, A., Depraetere, O., Vandamme, D., Smolders, E., y Muylaert, K. (2013). Influence of organic matter on flocculation of Chlorella vulgaris by calcium phosphate precipitation. Biomass and bioenergy, 54, 107-114

Bilanovic, D., Shelef, G. y Sukenik, A. (1988). Flocculation of microalgae with cationic polymerseffects of medium salinity. Biomass. 17(1), 65-76. 
LÍNEA DE INVESTIGACIÓN: APROVECHAMIENTO DE RESIDUOS AGROINDUSTRIALES

Billuri, M., Bonner, J., Fuller, Ch., y Islam, M. (2015). Impact of Natural Cationic Polymers on Charge and Clarification of Microalgae Suspensions. Environmental engineering science, 32(3), 212-22.

Chatsungnoen, T., y Chisti, Y. (2016). Harvesting microalgae by flocculation-sedimentation. Algal Research, 13, 271-283

Chen, L., Wang, C., Wang, W., y Wei, J. (2013). Optimal conditions of different flocculation methods for harvesting Scenedesmus sp. cultivated in an open-pond system. Bioresource Technology, 133, 9-15

Cheng, Y., Zheng, Y., Labavitch, J., y Vandergheynst, J. (2011). The impact of cell wall carbohydrate composition on the chitosan flocculation of Chlorella. Process Biochemistry, 46(10), $1927-$ 1933.

Delrue, F., Imbert, Y., Fleury, G., Peltier, G., y Sassi, J. (2015). Using coagulation-flocculation to harvest Chlamydomonas reinhardtii: Coagulant and flocculant efficiencies, and reuse of the liquid phase as growth medium. Algal research, 9, 283-290

Endut, A., Hamid, S., Lananan, F., y Kathoon, H. (2016). Moringa oleifera seed derivatives as potential biocoagulant for microalgae Chlorella sp. Harvesting. Malaysian Journal of Analytical Sciences, 20(2), 401-412.

Gerde, J., Yao, L., Lio, J., Wen, Z., y Wang, T. (2013). Microalgae flocculation: Impact of flocculant type, algae species and cell concentration. Algal research, 3, 30-35.

Granados, M., Acien, G., Gómez, C., Fernández-Sevilla, J., y Molina Grima, E. (2012). Evaluation of flocculants for the recovery of freshwater microalgae. Bioresource Technology, 118, 102-110

Gutiérrez, R., Passos, F., Ferrer, I., Uggetti, E., y García, J. (2015). Harvesting microalgae from wastewater treatment systems with natural flocculants: Effect on biomass settling and biogas production. Algal research, 9, 204-211.

Hamid, S., Lananan, F., Khatoon, H., y Endut, A. (2016). A study of coagulating protein of Moringa oleifera in microalgae bio-flocculation. International Biodeterioration \& Biodegradation, 113, 310-317.

Hamid, S., Lananan, F., Din, W., Lam, S., Khatoon, H., Endut, A., y Jusoh, A. (2014). Harvesting microalgae, Chlorella sp. by bio-flocculation of Moringa oleifera seed derivatives from aquaculture wastewater phytoremediation. International Biodeterioration \& Biodegradation, 95, 270-275.

Hansel, P., Riefler, G. y Stuart, B. (2014). Efficient flocculation of microalgae for biomass production using cationic starch. Algal research, 5, 133-139. 
Harith, Z., Yussoff, F., Mohamed, M., Sharif, M., Din, M., y Ariff, A. (2009). Effect of different flocculants on the flocculation performance of microalgae, Chaetoceros calcitrans, cells. African Journal of Biotechnology, 8(21), 5971-5978.

Jiang, J., Graham, N., y Harward, C. (1993). Comparison of Polyferric Sulphate with Other Coagulants for the Removal of Algae and Algae-Derived Organic Matter. Water, science and technology, 27(11), 221-230.

Knuckey, R., Brown, M., Robert, R., y Frampton, D. (2006). Production of microalgal concentrates by flocculation and their assessment as aquaculture feeds. Aquacultural Engineering, 35(3), 300-313.

König, R., Sales, R., Roselet, F. y Abreu, P. (2014). Harvesting of the marine microalga Conticribra weissflogii (Bacillariophyceae) by cationic polymeric flocculants. Biomass and bioenergy, 68 , $1-6$.

Lavoie, A. y de la Noüe, J. (1983). Harvesting microalgae with chitosan. Journal of the world mariculture association, 14(1), 685-694.

Lecina, M., Nadal G., Solà, C., Prat, J., y Cairó, J. (2016). Optimization of ferric chloride concentration and $\mathrm{pH}$ to improve both cell growth and flocculation in Chlorella vulgaris cultures. Application to medium reuse in an integrated continuous culture bioprocess. Bioresource technology, 216, 211-218.

Lee, S., Kim, S., Kim, J., Kwon, G., Yoon, B., y Oh, H. (1998). Effects of harvesting method and growth stage on the flocculation of the green alga Botryococcus braunii. Letters in applied microbiology, 27(1), 14-18.

Lee, S., y Choi, H. (2015). Harvesting of microalgae species using Mg-sericite flocculant. Bioprocess and biosystems engineering, 38(12), 2323-2330.

Letelier-Gordo, C., Holdt, S., De Francisci, D., Karakashev, D., y Angelidaki, I. (2014). Effective harvesting of the microalgae Chlorella protothecoides via bioflocculation with cationic starch. Bioresource Technology, 167, 214-218.

Li, L., y Pan, G. (2013). A Universal Method for Flocculating Harmful Algal Blooms in Marine and Fresh Waters Using Modified Sand. Environmental Science and technology, 47(9), 45554562.

Morales, J., de la Noüe, J., y Picard, G. (1985). Harvesting marine microalgae species by chitosan flocculation. Aquacultural Engineering, 4(4), 257-270.

Moreno, L., Muñoz, E., y Casanova, H. (2015). Flocculation with Chitosan of Microalgae Native of the Colombian Plateau. Revista Ciencia en Desarrollo, 6(1), 25-31.

Papazi, A., Makridis, P., y Divanac, P. (2010). Harvesting Chlorella minutissima using cell coagulants. Journal of applied Phycology, 22, 349-355. 
LÍNEA DE INVESTIGACIÓN: APROVECHAMIENTO DE RESIDUOS AGROINDUSTRIALES

Pelton, R., y Allen, L. (1983). The effects of some polyelectrolytes on flocculation with a cationic polyacrylamide. Colloid Polymer science, 261(6), 485-492.

Pérez, L., Cancela, A., Maceiras, R., Salgueiro, J. y Sánchez, J. (2015). Selenastrum Capricornutum: Harvesting and Oil Extraction, for Biodiesel Production. European Journal of Sustainable Development, 4(2), 97-102.

Rashid, N., Rehman, S., y Han, J. (2013a). Rapid harvesting of fresh water microalgae using chitosan. Process Biochemistry, 48(7), 1107-1110.

Rashid, N., Rehman, S., y Han, J. (2013b). Use of chitosan acid solutions to improve separation efficiency for harvesting of the microalga Chlorella vulgaris. Chemical Engineering Journal, $226,238-242$.

Renault, F., Sancey, B. Badot, P., y Crini, G. (2009). Chitosan for coagulation/flocculation processes - An eco-friendly approach. European Polymer Journal, 45, 1337-1348.

Roselet, F., Vandamme, D., Roselet, M., Muylaert, K., y Abreu, P. (2015). Screening of commercial natural and synthetic cationic polymers for flocculation of fresh water and marine microalgae and effects of molecular weight and charge density. Algal research, 10(1), 183-188.

Roselet, F., Burkert, J., y Abreu, P. (2016). Flocculation of Nannochloropsis oculata using a tannin-based polymer: Bench scale optimization and pilot scale reproducibility. Biomass and Bioenergy, 87, 55-60.

Salama, E., Kim, J., Ji, M., Cho, D., Abou-Shanab, R., Kabra, A., y Jeon, B (2015). Application of acid mine drainage for coagulation/flocculation of microalgal biomass. Bioresource technology, $186,232-237$.

Schlesinger, A., Eisenstadt, D., Bar-Gil, A., Carmely, H., Einbinder, S., y Gressel, J. (2012). Inexpensive non-toxic flocculation of microalgae contradicts theories; overcoming a major hurdle to bulk algal production. Biotechnology Advances, 30(5), 1023-1030.

Seo, Y., Park, D., Oh, y., Yoon, S., y Han, J. (2015). Harvesting of microalgae cell using oxidized dye wastewater. Bioresource Technology, 192, 802-806.

Shelef, G., Sukenik, A., y Green, L. (1984). Microalgae harvesting and processing: a literature review. Departamento de Comercio de Estados Unidos. Recuperado de: http://www.nrel.gov/ docs/legosti/old/2396.pdf

Şirin, S., y Sillanpää, M. (2015). Cultivating and harvesting of marine alga Nannochloropsis oculata in local municipal wastewater for biodiesel. Bioresource Technology, 191, 79-87.

Şirin, S., Clavero, E., y Salvadó, J. (2015). Efficient harvesting of Chaetoceros calcitrans for biodiesel production. Environmental Technology, 36(15), 1-32. 
Sukenik, A., Bilanovic, D., y Shelef, G. (1988). Flocculation of microalgae in brackish and sea waters. Biomass, 15(3), 187-199.

Teixeira, C., Kirsten, F., y Teixeira, P. (2012). Evaluation of Moringa oleifera seed flour as a flocculating agent for potential biodiesel producer microalgae. Journal of applied Phycology, 24(3), 557-563.

Tenney, M., Echelberger, W., Schuessler, R., y Pavoni, J. (1969). Algal flocculation with synthetic organic polyelectrolytes. Applied microbiology, 18(6), 965-971.

Tilton, R., Murphy, J., y Dixon, J. (1972). The flocculation of algae with synthetic polymeric flocculants. Water Research, 6(2), 155-164.

T'Lam, G., Vermuë, M., Olivieri, G., van den Broek, L., Barbosa, M., Eppink, M., Wijffels, R., y Kleinegris, D. (2014). Cationic polymers for successful flocculation of marine microalgae. Bioresource Technology, 169, 804-807.

T'Lam, G., Zegeye, E., Vermuë, M., Kleinegris, D., Eppink, M., Wijffels, R., y Olivieri, G. (2015). Dosage effect of cationic polymers on the flocculation efficiency of the marine microalga Neochloris oleoabundans. Bioresource Technology, 198, 797-802.

Udhaya, R., Benedict, L., y Sandhya, S. (2014). Evaluation of chemical flocculation-electroflocculation for harvesting of halotolerant microalgae. International Journal of environmental sciences, 4(5), 899-905.

Vandamme, D., Foubert, I., Meesschaert, B., y Muylaert, K. (2010). Flocculation of microalgae using cationic starch. Journal of applied Phycology, 22, 525-530.

Vandamme, D. (2013). Flocculation based harvesting processes for microalgae biomass production (tesis doctoral). Arenberg Doctoral School, Bélgica.

Vandamme, D., Foubert, I., y Muylaert, K. (2013). Flocculation as a low cost method for harvesting microalgae for bulk biomass production. Trends in biotechnology, 31(4), 233-239.

Zheng, H., Gao, Z., Yin, J., Tang, X., Ji, X., y Huang, H.(2012). Harvesting of microalgae by flocculation with poly (a-glutamic acid). Bioresource Technology, 112, 212-220.

Zhu, Y., Dunford, T., y Goad, C. (2013). Effect of Processing Parameters on Flocculation of Picochlorum oklahomensis. Journal of the American Oil Chemists Society, 91(2), 317-324. 